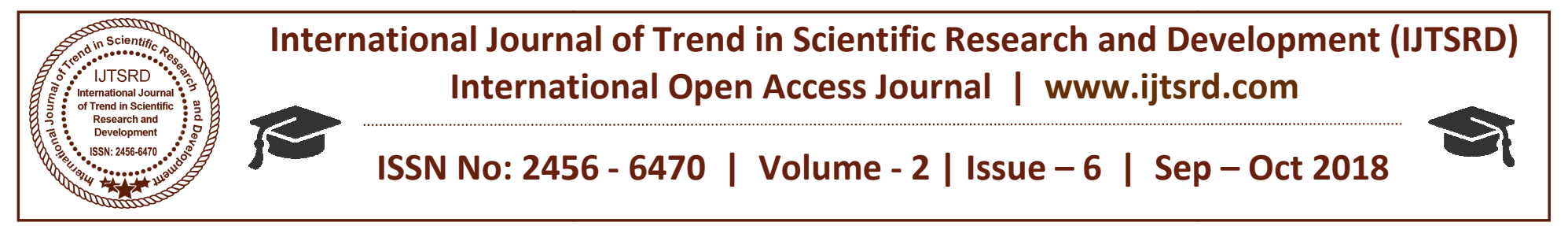

\title{
Performance Evaluation of Coating Materials and Process Parameters Optimization for Surface Quality During Turning of Aisi 410 Austenitic Stainless Steel
}

\author{
C. Amarnath ${ }^{1}$, Mr. A. Harinath ${ }^{2}$, Mr. N. Phani Raja Rao ${ }^{2}$ \\ ${ }^{1}$ PG. Scholar, ${ }^{2}$ Assistant Professor \\ Sri Venkateswara Institute of Technology, Anantapuram, Andhra Pradesh, India
}

\begin{abstract}
Stainless steel (SS) is used for many commercial and industrial applications owing to its high resistance to corrosion. It is too hard to machine due to its high strength and high work hardening property. A surface property such as surface roughness (SR) is critical to the function-ability of machined components.
\end{abstract}

Stainless steel is generally regarded as more difficult to machine material and poor SR is obtained during machining. In this paper an attempt has been made to investigate the SR produced by $\mathrm{CNC}$ turning on austenitic stainless steel (AISI316) and martensitic stainless steel (AISI410) by different cases of coated cutting tool used at dry conditions. Multi-layered coated with TiCN/Al2O3, multi-layered coated with $\mathrm{Ti}(\mathrm{C}, \mathrm{N}, \mathrm{B})$ and single layered coated with TiAlN coated cutting tools are using.

Experiments were carrying out by using Taguchi's L27 orthogonal array. The effect of cutting parameters on SR is evaluated and optimum cutting conditions for minimizing the SR are determined. Analysis of variance (ANOVA) is used for identifying the significant parameters affecting the responses. Confirmation experiments are conduct to validate the results obtaining from optimization.

Keywords: CNC turning, AISI316, AISI410, roughness, Taguchi's Techniques, ANOVA.

\section{INTRODUCTION}

The 1980s have witnessed a fundamental change in the way governments and development agencies think about environment and development. The two are no longer regarded as mutually exclusive. It has been recognized that a healthy environment is essential for a healthy economy. Energy and materials are the two primary inputs required for the growth of any economy and these are obtained by exploiting the natural resources like fossil fuels and material ores. The industrial sector accounts for about one-half of the world's total energy consumption and the consumption of energy by this sector has almost doubled over the last 60 years (Fang et al.,).

The consumption of critical raw materials (steel, aluminum, copper, nickel, zinc, wood, etc.) for industrial use has increased worldwide. The rapid growth in manufacturing has created many economic, environmental and social problems from global warming to local waste disposal (Sangwan). There is a strong need, particularly, in emerging and developing economies to improve manufacturing performance so that there is less industrial pollution, and less material \& energy consumption. Energy efficiency and product quality have become important benchmarks for assessing any industry.

Manufacturing operations account for $37 \%$ of global energy demand (Diaz-Elsayed et al.,). U.S. manufacturing industry annually consumes 21.1 quadrillion BTU energy (about $21 \%$ of total U.S. energy consumption) and generates more than 1.4 Surfaballion metric tons of $\mathrm{CO}_{2}$ emissions (about 26\% of total U.S. $\mathrm{CO}_{2}$ emissions) (Yuan et al.,). Machine tools have less than $30 \%$ efficiency (He et al.) and more than $99 \%$ of the Environmental impacts are due to the consumption of electrical energy used by the machine tools in discrete part manufacturing machining processes like turning and milling ( $\mathrm{Li}$ et al.). 
Worldwide, machine tool manufacturing is a USD 68.6 billion industry and very few energy assessments have been conducted for discrete manufacturing facilities (Diaz-Elsayed et al.). Sustainability performance of machining processes can be achieved by reducing the power consumption (CamposecoNegrete,). If the energy consumption is reduced, the environmental impact generated from power production is diminished (Pusavec et al.,). Sustainability performance may be reduced artificially by increasing the surface roughness as lower surface finish requires lesser power and resources to finish the machining.

However, this may lead to more rejects, rework and time. Therefore, an optimum combination of power and surface finish is desired for sustainability performance of the

machining processes. There is a close interdependence among productivity, quality and power consumption of a machine tool. The surface roughness is widely used index of product quality in terms of various parameters such as aesthetics, corrosion resistance, subsequent processing advantages, tribological considerations, fatigue life improvement, precision fit of critical mating surfaces, etc. But the achievement of a predefined surface roughness below certain limit generally increases power consumption exponentially and decreases the productivity.

The capability of a machine tool to produce a desired surface roughness with minimum power consumption depends on machining parameters, cutting phenomenon, work piece properties, cutting tool properties, etc. The first step towards reducing the power consumption and surface roughness in machining is to analyze the impact of machining parameters on power consumption and surface roughness.

\section{EXPERIMENTAL SETUP AND PLAN Introduction}

Predictive modeling and optimization require selection of appropriate sets of machining parameters of the process. This can mainly be achieved by understanding the interrelationship among the large number of parameters affecting the process and identifying the optimal machining conditions. Experiments are performed on a given machine tool in order to understand the effect of different process parameters on performance characteristics i.e. surface roughness and power consumption.

\section{Material}

The sample material for the research is AISI 1045 steel. There is a renewed interest in the application of this steel because of its sustainability. It is $100 \%$ recyclable and almost has indefinite life cycle. AISI 1045 steel is one of the steel grades widely used in different industries (construction, transport, automotive, power, etc.). Some of the commonly used components of 1045 steel are gears, shafts, axles, bolts, studs, connecting rods, spindles, rams, hydraulic pumps, etc. The chemical composition and mechanical properties of the AISI 1045 steel are given in Table 3.1 and Table 3.2 respectively.

Therefore, $10 \mathrm{~mm}$ steps were provided on the work piece as shown in the figure. A pre-cut of $1.5 \mathrm{~mm}$ depth was performed on each work piece prior to actual turning using a different cutting tool. This was done in order to remove the rust or hardened top layer from the surface and to minimize any effect of nonhomogeneity on the experimental results.

Table 1: Chemical composition of AISI 1045 steel in percentage weight

\begin{tabular}{|c|c|c|c|c|c|}
\hline Material & C \% & Mn \% & P \% & s\% & Si \% \\
\hline AISI 1045 Steel & 0.43 & 0.7 & 0.04 & 0.05 & 0.16 \\
\hline
\end{tabular}

Table 2: Mechanical properties of AISI 1045 steel

\begin{tabular}{|c|c|c|c|c|c|c|}
\hline Material & $\begin{array}{c}\text { Density } \\
\left(\mathrm{kg} / \mathrm{m}^{3}\right)\end{array}$ & $\begin{array}{c}\text { Elastic modulus } \\
(\mathbf{G p a})\end{array}$ & $\begin{array}{c}\text { Yield } \\
\text { Strength (Mpa) }\end{array}$ & $\begin{array}{c}\text { Tensile } \\
\text { Strength (Mpa) }\end{array}$ & $\begin{array}{c}\text { Hardness } \\
(\text { HB) }\end{array}$ & $\begin{array}{c}\text { Elongation } \\
\text { ratio }\end{array}$ \\
\hline AISI 1045 Steel & 7.8 & 205 & 505 & 585 & 170 & 1.2 \\
\hline
\end{tabular}

\section{Cutting Tool Inserts and Holder}

Uncoated tungsten carbide tools were used for the experiments. The cutting tool used is proper for machining of AISI 1045 steel with ISO P25 quality. Sandvik inserts with the ISO TNMG $16 \quad 04 \quad 12$ designation were mounted on the tool holder designated by ISO as PTGNR 2020 K16 having rake angle of $7^{0}$, clearance angle of $6^{\circ}$ and $0.4 \mathrm{~mm}$ nose radius. An insert mounted on the tool holder is shown in Figure. 


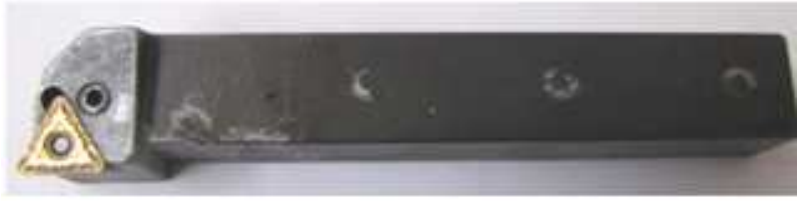

Figure 1: Insert mounted on the tool holder Machine Tool

The turning experiments were carried out in dry cutting conditions using an HMT centre lathe. It has a maximum spindle speed of $2300 \mathrm{rpm}$ and spindle power of $5.5 \mathrm{~kW}$. Work piece was held between chuck and tailstock; and the tool overhang was kept $20 \mathrm{~mm}$ to increase rigidity of the machining system as shown in Figure 2.

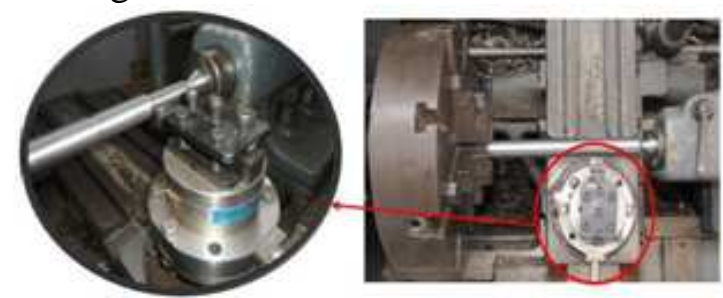

Figure 2: Tool overhung and work piece clamped between chuck and tailstock

The experiments were conducted by turning the work piece with feed direction towards the chuck of the lathe (referred to as "left feed direction") as is often the case during conventional turning.

\section{SELECTION OF MACHINING PARAMETERS AND THEIR LEVELS}

The choice of machining parameters was made by taking into account the capacity/limiting cutting conditions of the lathe, tool manufacturer's catalogue and the values taken by researchers in the literature.
Cutting speed $(v)$, feed rate $(f)$ and depth of cut $(d)$ are the input parameters chosen for the research. The performance characteristics chosen to investigate the effect of machining parameters were surface roughness $\left(\mathrm{R}_{\mathrm{a}}\right)$ and power consumption $(\mathrm{P})$. Table 3.3 shows the three machining parameters and the three levels for each parameter.

Table 3: Machining parameters and their levels

\begin{tabular}{|c|c|c|c|c|}
\hline Factor & Symbol & $\begin{array}{c}\text { Level } \\
1\end{array}$ & $\begin{array}{c}\text { Level } \\
\mathbf{2}\end{array}$ & $\begin{array}{c}\text { Level } \\
\mathbf{3}\end{array}$ \\
\hline $\begin{array}{c}\text { Cutting } \\
\text { speed } \\
\text { (m/min) }\end{array}$ & $v$ & 103.31 & 134.30 & 174.14 \\
\hline $\begin{array}{c}\text { Feed rate } \\
\text { (mm/rev. })\end{array}$ & $f$ & 0.12 & 0.16 & 0.2 \\
\hline $\begin{array}{c}\text { Depth of cut } \\
\text { (mm) }\end{array}$ & $d$ & 0.5 & 1.0 & 1.5 \\
\hline
\end{tabular}

\section{Experimental Design}

In any experimental investigation, the results depend to a large extent on the data collection methodology. The most preferred method of experimentation utilized by researchers is a full factorial set of experiments, where experiments are carried out for all combinations of variables. A full factorial design of experiments (DOE) measures the response of every possible combination of factors and factor levels. These responses are analyzed to provide information about every main effect and every interaction effect. The experimental design for three turning parameters $(v, f, d)$ with three levels $\left(3^{3}\right)$ are organized by the Taguchi's $\mathrm{L}_{27}$ orthogonal array as shown in Table.

Table 4: An $\mathrm{L}_{27}$ Orthogonal array

\begin{tabular}{|c|c|c|c|c|c|c|c|c|c|c|c|c|c|}
\hline \multirow{2}{*}{$\begin{array}{l}\text { Experiment } \\
\text { No. }\end{array}$} & \multicolumn{13}{|c|}{ Column Number } \\
\hline & 1 & 2 & 3 & 4 & 5 & 6 & 7 & 8 & 9 & 10 & 11 & 12 & 13 \\
\hline 1 & 1 & 1 & 1 & 1 & 1 & 1 & 1 & 1 & 1 & 1 & 1 & 1 & 1 \\
\hline 2 & 1 & 1 & 1 & 1 & 2 & 2 & 2 & 2 & 2 & 2 & 2 & 2 & 2 \\
\hline 3 & 1 & 1 & 1 & 1 & 3 & 3 & 3 & 3 & 3 & 3 & 3 & 3 & 3 \\
\hline 4 & 1 & 2 & 2 & 2 & 1 & 1 & 1 & 2 & 2 & 2 & 3 & 3 & 3 \\
\hline 5 & 1 & 2 & 2 & 2 & 2 & 2 & 2 & 3 & 3 & 3 & 1 & 1 & 1 \\
\hline 6 & 1 & 2 & 2 & 2 & 3 & 3 & 3 & 1 & 1 & 1 & 2 & 2 & 2 \\
\hline 7 & 1 & 3 & 3 & 3 & 1 & 1 & 1 & 3 & 3 & 3 & 2 & 2 & \\
\hline 8 & 1 & 3 & 3 & 3 & 2 & 2 & 2 & 1 & 1 & 1 & 3 & 3 & 3 \\
\hline 9 & 1 & 3 & 3 & 3 & 3 & 3 & 3 & 2 & 2 & 2 & 1 & 1 & 1 \\
\hline 10 & 2 & 1 & 2 & 3 & 1 & 2 & 3 & 1 & 2 & 3 & 1 & 2 & 3 \\
\hline 11 & 2 & 1 & 2 & 3 & 2 & 3 & 1 & 2 & 3 & 1 & 2 & 3 & 1 \\
\hline 12 & 2 & 1 & 2 & 3 & 3 & 1 & 2 & 3 & 1 & 2 & 3 & 1 & 2 \\
\hline 13 & 2 & 2 & 3 & 1 & 1 & 2 & 3 & 2 & 3 & 1 & 3 & 1 & \\
\hline
\end{tabular}




\begin{tabular}{|l|l|l|l|l|l|l|l|l|l|l|l|l|l|}
\hline 14 & 2 & 2 & 3 & 1 & 2 & 3 & 1 & 3 & 1 & 2 & 1 & 2 & 3 \\
\hline 15 & 2 & 2 & 3 & 1 & 3 & 1 & 2 & 1 & 2 & 3 & 2 & 3 & 1 \\
\hline 16 & 2 & 3 & 1 & 2 & 1 & 2 & 3 & 3 & 1 & 2 & 2 & 3 & 1 \\
\hline 17 & 2 & 3 & 1 & 2 & 2 & 3 & 1 & 1 & 2 & 3 & 3 & 1 & 2 \\
\hline 18 & 2 & 3 & 1 & 2 & 3 & 1 & 2 & 2 & 3 & 1 & 1 & 2 & 3 \\
\hline 19 & 3 & 1 & 3 & 2 & 1 & 3 & 2 & 1 & 3 & 2 & 1 & 3 & 2 \\
\hline 20 & 3 & 1 & 3 & 2 & 2 & 1 & 3 & 2 & 1 & 3 & 2 & 1 & 3 \\
\hline 21 & 3 & 1 & 3 & 2 & 3 & 2 & 1 & 3 & 2 & 1 & 3 & 2 & 1 \\
\hline 22 & 3 & 2 & 1 & 3 & 1 & 3 & 2 & 2 & 1 & 3 & 3 & 2 & 1 \\
\hline 23 & 3 & 2 & 1 & 3 & 2 & 1 & 3 & 3 & 2 & 1 & 1 & 3 & 2 \\
\hline 24 & 3 & 2 & 1 & 3 & 3 & 2 & 1 & 1 & 3 & 2 & 2 & 1 & 3 \\
\hline 25 & 3 & 3 & 2 & 1 & 1 & 3 & 2 & 3 & 2 & 1 & 2 & 1 & 3 \\
\hline 26 & 3 & 3 & 2 & 1 & 2 & 1 & 3 & 1 & 3 & 2 & 3 & 2 & 1 \\
\hline 27 & 3 & 3 & 2 & 1 & 3 & 2 & 1 & 2 & 1 & 3 & 1 & 3 & 2 \\
\hline
\end{tabular}

\section{Power Consumption Measurement}

The power consumption has been measured through the indirect method by measuring the cutting forces. In literature there are two methods - direct method using wattmeter or power sensor. Both methods have their own advantages and limitations. The direct method measures exactly the power required by the machine tool "system" including auxiliary power. This research aims at developing a relationship between cutting parameters and process performance (power and surface roughness during cutting).

The auxiliary power measurement does not add any value. An indirect method of power measurement by measuring the cutting forces was used to measure the power consumed during the experimentation. The schematic to measure the forces is shown in Figure. Kistler 9272 dynamometer, shown in Figure, is used to capture the force signals during the cutting process in $\mathrm{X}, \mathrm{Y}$ and $\mathrm{Z}$ directions (feed force, thrust force and cutting force). The dynamometer consists of threecomponent force sensors fitted under high preload between a base plate and a top plate. Each sensor contains three pairs of quartz plates, one sensitive to pressure in the $\mathrm{Z}$ direction and the other two responding to shear in the $\mathrm{X}$ and $\mathrm{Y}$ directions.

The specifications of the dynamometer are illustrated in Table. The calibration of dynamometer is done by applying known weights and collecting the measured data. The load is varied from 0 to $1500 \mathrm{~N}$ in the $\mathrm{Z}$ direction. The calibration was done for both loading and unloading conditions, so that any hysteresis in the measurement can be observed. No hysteresis was observed for the cutting force calibration. The cutting tool was mounted on the top of the dynamometer.
The amplifier amplifies the electrical charges delivered from the dynamometer and converts them into proportional forces using data acquisition system and then these forces are processed using Dynoware software. The cutting force is obtained based on the average of steady state region values of cutting operation as shown in Figure 3.7. The data collected from an unsteady state can result in inaccurate values, which can affect the analysis. Out of the three force components, cutting force is used to calculate the power required to perform the machining operation. Power is the product of cutting force and cutting speed and is a better criterion for design and selection of any machine tools. The machining parameters and the corresponding measured cutting force and calculated power values are given in Table.

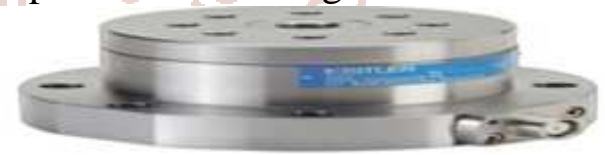

Fig3. Kistler 9272 dynamometer

\section{Result \& discussion}

The relative importance among the machining parameters $(v, f, d)$ for the multiple performance characteristics ( $\mathrm{Ra}$ and $\mathrm{P}$ ) needs to be investigated so that the optimal parameters can be decided effectively. The analysis of variance (ANOVA) has been applied to investigate the developed model and the effect of machining parameters on the multiobjective function. Table 6.5 shows ANOVA results for the linear $[v, f, d$,$] quadratic \left[v^{2}, f^{2}, d^{2}\right]$ and interactive $[(v \times f),(v \times d),(f \times d)]$ factors. F-value, which is a ratio of the regression mean square to the mean square error, is used to measure the significance of the model under investigation with respect to the variance of all the terms including the error term at the desired significance level. 
International Journal of Trend in Scientific Research and Development (IJTSRD) ISSN: 2456-6470

Table 5: Analysis of variance (ANOVA) for multi-objective function

DF: Degree of freedom, SS: Sum of square, MS: Mean square

\begin{tabular}{|c|c|c|c|c|c|c|c|}
\hline Source & DOF & $\begin{array}{c}\text { Seq. } \\
\text { SS }\end{array}$ & $\begin{array}{c}\text { Adj. } \\
\text { SS }\end{array}$ & $\begin{array}{c}\text { Adj. } \\
\text { MS }\end{array}$ & F & p & $\begin{array}{c}\% \\
\text { contribution }\end{array}$ \\
\hline Regression & 9 & 0.6482 & 0.6482 & 0.0720 & 37.31 & 0.000 & 95.18 \\
\hline Linear & 3 & 0.6272 & 0.6258 & 0.2086 & 108.07 & 0.000 & 92.10 \\
\hline$V$ & 1 & 0.0172 & 0.0157 & 0.0157 & 8.13 & 0.011 & 2.53 \\
\hline$F$ & 1 & 0.4199 & 0.4197 & 0.4197 & 217.41 & 0.000 & 61.66 \\
\hline$D$ & 1 & 0.1901 & 0.1904 & 0.1904 & 98.65 & 0.000 & 27.91 \\
\hline Square & 3 & 0.0204 & 0.0204 & 0.0068 & 3.52 & 0.038 & 2.99 \\
\hline$v^{*} v$ & 1 & 0.0060 & 0.0060 & 0.0060 & 3.10 & 0.096 & 0.88 \\
\hline$f^{*} f$ & 1 & 0.0142 & 0.0142 & 0.0142 & 7.35 & 0.015 & 2.08 \\
\hline Interaction & 1 & 0.0002 & 0.0002 & 0.0002 & 0.10 & 0.752 & 0.03 \\
\hline$v^{* f}$ & 1 & 0.0007 & 0.0007 & 0.0002 & 0.12 & 0.948 & 0.11 \\
\hline$v^{*} d$ & 1 & 0.0004 & 0.0004 & 0.0004 & 0.20 & 0.661 & 0.06 \\
\hline$f^{*} d$ & 1 & 0.0001 & 0.0001 & 0.0001 & 0.06 & 0.807 & 0.02 \\
\hline Residual Error & 17 & 0.0328 & 0.0328 & 0.0019 & 0.05 & 0.802 & 4.82 \\
\hline Total & 26 & 0.681 & & & & & \\
\hline$R^{2}=0.9518$ & & & $R^{2}$ (Pred.) & 0.8743 & & $R^{2}($ Adj. $)=0.9263$ \\
\hline
\end{tabular}

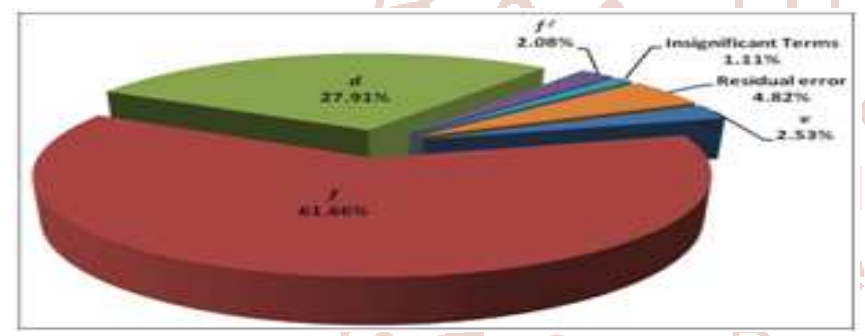

Figure 4: Percentage contribution of machining parameters on multi-objective function

The $\mathrm{p}$-value or probability value is used to determine the statistical significance of results at a confidence level. In this study the significance level of $\alpha=0.05$ is used, i.e. the results are validated for a confidence level of $95 \%$. If the $p$-value is less than 0.05 then the corresponding factor has a statistically significant contribution to the performance characteristic and if the $p$-value is more than 0.05 then it means the effect of factor on the performance characteristic is not statistically significant at $95 \%$ confidence level.

The results show that all linear terms and $f^{2}$ are statistically significant at $95 \%$ level. The last column of the Table 6.5 shows the percentage contribution of each term to the total variation indicating the degree of influence on the results. The percentage contribution of each term is also shown in Figure 6.3.

Feed $(f)$ was found to be the most significant machining parameter due to its highest percentage contribution of $61.66 \%$ followed by the depth of cut (d) with $27.91 \%$ and cutting speed (v) with $2.53 \%$. However, the percentage contribution of quadratic term $f^{2}$ is $2.08 \%$. As $R^{2}$ approaches unity, the response model fitness with the actual data improves. The value of $R^{2}$ obtained was 0.9518 which indicates that $95.18 \%$ of the total variations are explained by the model. The adjusted $R^{2}$ is a statistic used to adjust the "size" of the model, i.e. the number of factors (machining parameters). The value of the $R^{2}$ (Adj.) = 0.9263 indicating $92.63 \%$ of the total variability is explained by the model after considering the significant factors. $R^{2}$ (Pred.) $=87.43 \%$ is in good agreement with the $R^{2}$ (Adj.) and shows that the model would be expected to explain $87.43 \%$ of the variability in new data.

\section{Conclusions}

This study presents predictive and optimization models for the prediction and optimization of machining parameters leading to least power consumption and surface roughness during turning of AISI 1045 steel using tungsten carbide tools. Taguchi's orthogonal array to acquire the power consumption and surface roughness data. The developed predictive and optimization models based on experimental data, assist not only in analyzing the influence of the different process parameters on the two most dominant machining criteria, but are also useful for the optimality search of the various parametric combinations for achieving the maximum fulfillment of the objective requirements. 


\section{REFERENCES}

1. Kant, G., Sangwan, K.S., 2014. Prediction and optimization of machining parameters for minimizing power consumption and surface roughness in machining. Journal of Cleaner Production 83, 151-164.

2. Kant, G., Sangwan, K.S., 2015. Predictive modelling for power consumption in machining using artificial intelligence techniques. Procedia CIRP 26, 403-407.

3. Kant, G., Sangwan, K.S., 2015. Predictive modelling and optimization of machining parameters to minimize surface roughness using artificial neural network coupled with genetic algorithm. Procedia CIRP 31, 448-453.

4. Kant, G., Sangwan, K.S., 2015. Predictive modelling for energy consumption in machining using artificial neural network. Procedia CIRP 37, 205-210.

5. Sangwan, K.S., Saxena, S., Kant, G., 2015. Optimization of machining parameters to minimize surface roughness using integrated ANN-GA approach. Procedia CIRP 29, 305-310.

6. Kant, G., Rao V, V., Sangwan, K.S., 2013. Predictive modelling of turning operations using response surface methodology. Applied Mechanics and Materials 307, 170-173. 